\title{
Incarceration history relative to health, substance use, and violence in a sample of vulnerable South African women: implications for health services in criminal justice settings
}

\author{
This article was published in the following Dove Press journal: \\ Substance Abuse and Rehabilitation \\ 28 January 2012 \\ Number of times this article has been viewed
}

\author{
Jennifer E Johnson' \\ Tara Carney ${ }^{2}$ \\ Tracy Kline ${ }^{3}$ \\ Felicia A Browne \\ Wendee MWechsberg ${ }^{4}$ \\ 'Department of Psychiatry and \\ Human Behavior, Brown University, \\ Providence, RI, USA; ${ }^{2}$ Alcohol and \\ Drug Abuse Research Unit, Medical \\ Research Council, Cape Town, \\ South Africa; ${ }^{3}$ Statistics and \\ Epidemiology, RTI International, \\ Research Triangle Park, NC, USA; \\ ${ }^{4}$ Substance Abuse Treatment \\ Evaluations and Interventions, RTI \\ International, Research Triangle Park, \\ NC, USA
}

Correspondence: Jennifer E Johnson 700 Butler Drive, Providence, RI 02906, USA

Tel + I 40I 444 I9I6

Fax +I 4014441948

Email jennifer_johnson@brown.edu

\begin{abstract}
International research has suggested that women in the criminal justice system carry a higher burden of many illnesses than women in the community, especially mental health disorders, substance use disorders, sexually transmitted infections, and a history of violent victimization. Knowledge of these health disparities is often used to advocate for relevant screening and treatment services for women passing through criminal justice custody within US and European settings. However, almost all criminal justice health research has taken place in high-income countries, with little or no research taking place in other countries, especially in South Africa. This baseline analysis compares the health, substance use, and violent victimization of women who have ever been incarcerated to those who have not, in a cross-sectional sample of 720 young, vulnerable, substance-using women in Cape Town, South Africa. Results of univariate tests indicated that women who had ever been incarcerated had worse health, mental health, and sexually transmitted infection indicators and were more likely to report use of substances and to have been victims of physical and sexual assault than women who had never been incarcerated. Passing through the criminal justice system appears to be a marker for a variety of current and/or future health service needs among vulnerable South African women, suggesting that screening, prevention, and treatment referral efforts at the time of intersection with the criminal justice system may reduce health burden for these women.
\end{abstract}

Keywords: criminal justice, women, South Africa, mental health, HIV, trauma

\section{Introduction}

Research on women in the criminal justice system has suggested that they carry a higher burden of many illnesses, especially mental health, substance use, and infectious diseases, than women who have had no contact with the criminal justice system. ${ }^{1}$ In addition, women who pass through the criminal justice system are much more likely than other women to have been victims of interpersonal violence. ${ }^{2}$ Knowledge of these health disparities is used to advocate for mental health, substance use, and infectious disease screening and treatment services for women passing through criminal justice custody. However, almost all research on the health of women in correctional systems has taken place in high-income countries with little or no research taking place in other countries, ${ }^{1}$ especially in South Africa.

\section{Criminal justice and healthcare in South Africa}

South Africa is one of 13 countries with an incarcerated population of more than $100,000^{1,3}$ and an incarceration rate that is high $\left(413\right.$ per $\left.100,000^{4}\right)$ relative to the mean 
of 145 per 100,000 worldwide. ${ }^{1,3}$ Women who are sentenced or awaiting trial make up a relatively small percentage $(2.3 \%$; 3762 of the 162,162 daily census) of the total inmate population in South Africa. ${ }^{5}$ Common offenses for which South African women are incarcerated (including both sentenced and unsentenced women) include economic offenses (45\%), aggressive offenses (37\%) and, to a lesser degree, drugrelated offenses $(10 \%){ }^{6}$ Women may be incarcerated for lengths of time ranging from a few hours (if arrested and released) to decades. ${ }^{7}$ Although there are dramatic racial disparities in incarceration rates in some countries such as the United States, ${ }^{8}$ incarcerated women in South Africa, compared with the general South African female population, are slightly less likely to be Black African (68\% vs $79 \%$ ), equally likely to be White ( $8 \%$ and $9 \%)$, and slightly more likely to be Coloured (the South African term for mixed race; $21 \%$ vs $9 \%$ ) than are women in the general South African population. ${ }^{9,10}$

South African correctional facilities have been designed primarily to accommodate men and economies of scale have favored the provision of services to men. ${ }^{11}$ For example, of the 241 correctional facilities in South Africa, only eight house women exclusively, with another 91 men's facilities providing separate living quarters for women. ${ }^{5}$ Furthermore, laws about hygiene and health care for prisoners focus on primary health care and do not mention the provision of specific services or items to women. ${ }^{12}$

The idea of prisoner rights, including access to health care, is a reasonably new concept in South Africa. The South African criminal justice system has undergone a large transformation in the past two decades. Political prisoners were released from South African prisons in 1990 and prisoners of different races were housed together starting in $1993 .{ }^{12}$ The South African prison system was run by the military until 1996, and the criminal justice system was historically closed from any outside scrutiny, including research on prison health issues. ${ }^{12,13}$ With recent liberalization of laws and the new constitution, there is a certain new openness to issues of incarceration, ${ }^{11}$ and research relevant to South African criminal justice policy is beginning to be conducted.

The healthcare system in general in South Africa has also been undergoing a transformation since the end of Apartheid in 1994, including increasing the number of primary health care facilities and the introduction of free maternity and pediatric health care and other services. ${ }^{14}$ More recently, antiretroviral treatment for AIDS has been made available to selected public sector health facilities. ${ }^{14}$ While the South African government has been putting such policies into place in an attempt to redress inequities, there are still clear differences in rates of disease and mortality between races. ${ }^{15}$ Furthermore, massive gender inequalities also exist in terms of men's and women's health ${ }^{15}$ and access to health care, especially for previously disadvantaged women. Previous studies show that women face a number of barriers to receiving health care services, especially women who face multiple risks, such as HIV and substance use. ${ }^{16}$

\section{Mental health}

Research conducted in high-income countries has indicated that women in the criminal justice system are more at risk for depression, psychosis, personality disorder, and posttraumatic stress disorder. ${ }^{1,17-24}$ However, few studies of psychiatric morbidity and distress have been conducted outside high-income countries, especially in South Africa. ${ }^{1}$ One exception is a recent study conducted among a representative sample of women incarcerated in the South African province of Gauteng which found that $5 \%$ of the women reported past suicide attempts, 10\% had contemplated suicide, and 6\% currently used antidepressants or other medications to help them deal with their feelings. ${ }^{3}$ These findings suggest that some women passing through the criminal justice system in South Africa have mental health problems, but additional information is needed.

\section{Substance misuse}

Drug and alcohol problems are also common among women in contact with the criminal justice system in high-income countries. ${ }^{1,25}$ In South Africa, some studies ${ }^{26}$ have excluded women, but one large sample of male and female arrestees across three metro areas in South Africa found that $34 \%$ of the women in their sample tested positive for at least one drug (not including alcohol) at the time of arrest. ${ }^{27}$ Another study found that around half of a small sample of South African women incarcerated for murdering their partners considered themselves to have a substance use problem. ${ }^{28}$ These studies suggest that many women passing through criminal justice custody have problematic substance use, but more information on how substance use and substance use triggers differ between criminal justice involved women, and community women in South Africa, is needed to inform correctional substance use treatment services.

\section{Sexually transmitted infections (STIs) and overall health}

In the US, female inmates have higher rates of HIV, syphilis, and chlamydia than do male inmates and women in the 
community, ${ }^{29-32}$ with $50 \%$ of incarcerated women in the US self-reporting STI history. ${ }^{33,34}$ In South Africa, Goyer ${ }^{35}$ estimated the HIV prevalence among incarcerated populations to be about twice that of those of the same age and gender in the community (22\%), putting the estimated HIV prevalence in jails and prisons at around $44 \%$. Goyer also reported that most HIV in South Africa is sexually transmitted because intravenous drug use is not common. The association between STIs and criminal justice involvement among South African women is unknown.

Existing research, primarily from high-income countries, also finds higher rates of other infectious diseases (such as tuberculosis, hepatitis B, and hepatitis C) in criminal justice involved populations than in general populations. ${ }^{1,36}$ Although little research exists on the association between criminal justice involvement and most diseases in South Africa, one study of incarcerated South African women ${ }^{37}$ found that $44 \%$ described their health as fair or poor. ${ }^{38}$ In comparison, only $13 \%$ of a sample of community women described their health as average, poor, or very poor. ${ }^{39}$

\section{Physical and sexual violence}

A recent review of incarcerated women worldwide concluded that they have often experienced violent victimization, including childhood and adulthood physical and sexual abuse, but this review did not include data from South Africa. ${ }^{2}$ One study of South African women incarcerated in Gauteng found that many of them had experienced some kind of abuse, especially childhood rape and adulthood abuse by intimate partners. ${ }^{37,39,40}$ Another study found that around 5\% of incarcerated South African women had murdered their intimate partners, often after the partner abused the woman or her children and the woman had been refused help by family, friends, or the police, ${ }^{28}$ suggesting that victimization by and perpetration of partner violence poses a significant problem for some criminal justice-involved women in South Africa.

\section{Aims}

This study defines vulnerable women in South Africa to be those who live in disadvantaged communities, putting them at risk for a variety of health disparities. ${ }^{41}$ Work among vulnerable substance-involved community women in the Western Cape has suggested that they are at elevated risk for health problems including substance misuse, mental health problems, HIV and other STIs, and violent victimization. ${ }^{42-44}$ Previous work has examined the effects of an evidence-based, adapted intervention on drug use and sexual risk behavior among Black African and Coloured women in the Western
Cape, ${ }^{42}$ but this work did not examine differences among women who have and have not been involved with the criminal justice system. This paper builds upon these early findings by comparing a sample of women in the Western Cape who have passed through criminal justice custody to those who have not, using various health indicators to determine whether criminal justice custody would be an appropriate setting for screening and intervention efforts. If entering criminal justice custody is a marker for current or future health risk, identifying and addressing the health needs of women as they enter the criminal justice system could reduce the health burden for a particularly vulnerable group of women, and providing these services will be essential in creating a gender-sensitive, helpful environment.

The study tests the hypotheses that women who were ever incarcerated would be more likely to report symptoms of mental health distress, problematic substance use, self-reported STIs and HIV, violence and victimization, and poorer overall health than women with no history of incarceration. Furthermore, because mental health difficulties, violent victimization, and more severe substance use are more strongly associated with pain-alleviating than hedonic reasons for using substances, ${ }^{45-49}$ the study also tests the secondary hypothesis that women with an incarceration history would endorse more pain- and distress-related reasons for using substances than women with no history of incarceration. Thus, the study identifies health concerns that may be particularly prevalent among women passing through criminal justice custody, along with some preliminary information about substance use triggers that can be used to tailor treatment approaches for South African women passing through criminal justice custody.

\section{Method Participants}

Participants consisted of the baseline sample from the Western Cape Women's Health CoOp (WC-WHC) study, a 720-participant randomized controlled HIV prevention trial for young, substance-using women in Cape Town, South Africa (ClinicalTrials.gov registry number NCT00729391). This randomized controlled trial, funded by a grant from the Eunice Kennedy Shriver National Institute of Child Health and Human Development (NICHD R01 HD058320, Wechsberg, PI), began in September 2008 and ended recruitment in January 2011. To be eligible for the WC-WHC study, individuals had to meet these criteria:

1. Be female;

2. Be 18-33 years old; 
3. Live in or near any of the communities around the Cape Town airport;

4. Have been sexually active in the last 30 days with a male partner;

5. Used any of the following at least once a week in the past 3 months - alcohol, marijuana, methamphetamine, cocaine, heroin, methaqualone (mandrax), ecstasy, LSD, glue or other drug;

6. Did not participate in the pilot study of the Women's Health CoOp in Cape Town. ${ }^{42}$

\section{Procedures}

Women were recruited into the study via street outreach using a targeted sampling plan. Trained outreach workers approached women to ask if they could administer a quick field screener to determine preliminary eligibility. If women agreed to be screened, met the eligibility criteria, and were interested in participating in the study, they were scheduled for an intake appointment at the project field site. At this intake appointment, women were rescreened to determine final eligibility and, if eligible, their consent was recorded and they were enrolled into the study. RTI International's Institutional Review Board and Stellenbosch University's Committee for Human Research approved this study protocol.

\section{Assessments}

All items and subscales in this study come from the Pretoria Risk Behavior Assessment (PRBA), which was conducted at baseline by trained interviewers using Computer Assisted Personal Interviewing, taking approximately 90 minutes. The PRBA was adapted for South African women from the Revised Risk Behavior Assessment. ${ }^{50}$ Interviewers were peers (ie, Black African or Coloured women) from the community who were trained using a standard field manual. Interviewers completed several observed interviews during training and were periodically recorded thereafter for quality assurance. The PRBA, associated interviewing approach, and quality assurance procedures used in this study have been used in South Africa in numerous studies of female substance abusers with excellent data quality, reliability, and validity. ${ }^{51-53}$ Internal consistency for all PRBA subscales is 0.72 or higher. This paper examines baseline data from the larger study which also included assessments at 3, 6, 9, and 12 months post-enrolment.

History of criminal justice involvement (yes/no) was determined using a question that asked: "Have you ever spent time in jail or prison, including holding cells?"
Sample descriptors included race, age, years of education, whether or not the participant was employed in any capacity (including both full- and part-time employment), and current (within the past 6 months) engagement in illegal activities.

\section{Mental health}

In the PRBA, depressive symptoms are assessed using the 20-item Center for Epidemiological Studies Depression Scale (CES-D) ${ }^{54}$ anxiety symptoms are measured using an adapted version of the Drug Abuse Treatment for AIDS Risk Reduction (DATAR) Psychological Functioning Scale Anxiety Index, ${ }^{55}$ and post-traumatic stress disorder symptoms are assessed using Traumatic Distress Scale of the Global Appraisal of Individual Needs (GAIN). ${ }^{56}$

\section{Substance use}

Frequency and quantity of alcohol consumption was assessed: "frequent" drinking was defined as $2+$ drinking episodes per week and "extreme heavy" drinking was defined as $7+$ drinks per day. Past-month use of drugs including marijuana, methamphetamine ("Tik"), heroin, and methaqualone ("Mandrax") was also assessed ("How many days in the past month have you used___?"). Use of combined substances (such as a combination of marijuana and heroin called "Unga") was counted as use of both component substances (eg, marijuana and heroin) for these analyses. Women's reasons for using drugs were assessed using the PBRA subscale shown in Table 3. Items in this subscale had "yes", "no", and "unsure" response options.

\section{STIs and overall health}

As part of the PRBA, self-reported HIV status was assessed by asking, "Have you ever been tested for HIV?", and "Have you ever had an HIV test come back positive?". Participants were also asked whether they had experienced each of 12 common STI symptoms in the past 3 months; the number of STI symptoms was badly skewed, so it was dichotomized into less than two vs two or more STI symptoms. Participants rated their overall health on a scale from 1 (excellent) to 5 (poor).

\section{Physical and sexual violence}

Physical and sexual violence were also assessed using the PRBA. Violent victimization was assessed by questions asking about ever experiencing forced sex with one man, forced sex with more than one man, ever being physically hurt, and pushing, grabbing, shoving, or hitting one's main sexual partner in the past 30 days (see Table 1 for the wording of these questions). Abuse by a woman's current partner was assessed using a 14-item PRBA subscale based on the WHO 
Table I Participant characteristics by incarceration history $(n=720)$

\begin{tabular}{|c|c|c|c|}
\hline & $\begin{array}{l}\text { Ever incarcerated } \\
(n=25 I)\end{array}$ & $\begin{array}{l}\text { Never incarcerated } \\
(n=469)\end{array}$ & $\begin{array}{l}\text { Effect size } \\
\text { ( } 99 \% \text { confidence interval) }\end{array}$ \\
\hline \multicolumn{4}{|l|}{ Demographics } \\
\hline Black African vs coloured & $25.1 \%$ & $55.7 \% * * *$ & $\mathrm{OR}=0.27(0.17-0.42)$ \\
\hline Age & $23.8^{*}(4.2)$ & $22.8(4.3)$ & $\mathrm{d}=0.23(0.03-0.43)$ \\
\hline Years of education & $8.9(1.9)$ & $9.6 * * *(1.9)$ & $d=0.38(0.18-0.58)$ \\
\hline Unemployed & $94.0 \% *$ & $87.9 \%$ & $\mathrm{OR}=2.18(1.00-4.73)$ \\
\hline \multicolumn{4}{|c|}{ Current (past 6 month) criminal behavior } \\
\hline Possessed drugs & $54 \% * * *$ & $29 \%$ & $\mathrm{OR}=2.96(1.94-4.50)$ \\
\hline Been drunk in public & $35 \% * * *$ & $19 \%$ & $\mathrm{OR}=2.20(1.40-3.47)$ \\
\hline Been in a fight & $37 \% * * *$ & $16 \%$ & $\mathrm{OR}=3.15(2.00-5.02)$ \\
\hline Stolen anything & $20 \% * * *$ & $8 \%$ & $\mathrm{OR}=2.75(1.5 \mathrm{I}-5.0 \mathrm{I})$ \\
\hline Been involved in drug dealing/smuggling & $15 \% * * *$ & $5 \%$ & $\mathrm{OR}=3.46(1.69-7.06)$ \\
\hline
\end{tabular}

Notes: $* P<0.01$; $* * P<0.001$; $* * * P<0.0001$; values in the table represent means and standard deviations, unless otherwise noted.

Abbreviations: $d$, Cohen's d; OR, odds ratio.

violence against women instrument, ${ }^{57}$ which asked about the presence and frequency of emotional, physical, and sexual abuse during the past 6 months. Lifetime and past 6 month violent crime victimization was assessed on a PRBA subscale with items asking about instances of being beaten up, being forced to have sex, being cut by a knife, having money stolen, being chased, being shot at, and being threatened by a weapon. Verbal and physical aggression by the participant were measured using a PRBA subscale ${ }^{58}$ with 10 yes/no items asking whether women had used any of a list of aggressive behaviors (ranging from insulting or swearing at someone, to hitting someone or throwing things, to using a knife or gun) during a disagreement in the last 3 months.

\section{Analyses}

Analyses compared demographic, health variables (mental health, substance use, STIs, overall health), exposure to physical and sexual violence, and drug use triggers between participants who had ever been incarcerated (eg, spent time in jail, prison, or a holding cell) vs those who had never been incarcerated. Analyses of dichotomous variables used chi-square tests. After checking distributional assumptions, analysis of continuous variables used $t$ tests. Effect sizes were reported as odds ratios (OR; with confidence intervals) for dichotomous variables and Cohen's $\mathrm{d}$ for continuous variables. Analyses used a $P=0.01$ significance level (and reported a $99 \%$ confidence interval) to adjust for multiple comparisons. Because data were taken from the study's baseline interviews, few variables had missing data. No cases of the comparison variable (ever spent time in jail, prison, or a holding cell) were missing. "Missingness", when present, was addressed through case-by-case exclusion. Unless otherwise noted in the tables, all analyses included data from all 720 participants.

\section{Results}

For the parent study, a total of 1098 women were screened and 851 of those screened were eligible. Of those eligible, 720 expressed an interest in participation in the parent HIV prevention study, completed the study intake, and were enrolled. All women $(n=720)$ included in the baseline sample were included in this secondary analysis focusing on the correlates of past criminal justice involvement.

\section{Incarceration history}

About one-third ( $\mathrm{n}=251$ or $35 \%$ ) of the sample had ever been incarcerated (spent time in a jail or prison, including holding cells). The amount of time spent in correctional custody varied: $5 \%$ spent less than a day, $21 \%$ spent 1 day, $41 \%$ spent 2 days to a week, $12 \%$ spent 8 days to 1 month, $15 \%$ spent 31 days to a year, and $6 \%$ had spent more than a year incarcerated cumulatively over their lifetimes.

\section{Sample description}

Although race was not an inclusion criterion for the study, all women in the sample were Black African or Coloured. As shown in Table 1, women with an incarceration history were more likely to be Coloured and never incarcerated women were more likely to be Black African. Ever incarcerated women were slightly older (23.8 years vs 22.8 years), were less educated, and were less likely to be employed than never incarcerated women. Most women in the sample had a main sexual partner but were not married (91\%), with a few (5\%) married women and a few (4\%) women without partners in the sample. There were no differences in partner status by incarceration history. The most common current illegal activities in the sample are also shown in Table 1. Women with a lifetime history of 
incarceration had higher rates of past 6 month participation in common illegal activities than did women without an incarceration history.

\section{Mental health}

Current mental health among ever incarcerated women was poorer than among never incarcerated women on all measured indicators: women with a history of incarceration endorsed more current symptoms of depression, anxiety, and post-traumatic stress disorder than those without a history of incarceration (see Table 2).

\section{Substance use}

Women with a history of incarceration were more likely to report extreme heavy drinking and to have used methamphetamine or Mandrax (methaqualone tablets that are crushed and smoked) in the past 30 days than those without a history of incarceration (see Table 2). The use of heroin was equivalently low in both groups, rates of use of cannabis were equivalently high across groups, and rates of frequent drinking (two or more times per week) were equivalently moderate across groups (see Table 2). As expected, women with a history of incarceration were more likely to report using drugs in response to pain or distress (arguments, sadness, stress, feeling "you are letting yourself down," anger, physical pain, or trouble sleeping), but were not more likely to report using drugs for fun or pleasure (see Table 3) than were other women. Previously incarcerated women were also more likely to use drugs in response to urges or drinking/using other substances than were women with no incarceration history.

\section{STIs and overall health}

Women with a history of incarceration were more likely to report having two more current STI symptoms and they reported poorer overall health than never incarcerated women (see Table 2). However, there were no differences between the groups on HIV testing rates or self-reported HIV status (see Table 2).

\section{Physical and sexual violence}

Women who had ever been incarcerated reported dramatically higher rates of being struck or beaten to the point they had bruises than did women with no history of incarceration $(60 \%$ vs 29\%; see Table 4). They also reported more abuse from current partners and were more likely to have been both lifetime and recent victims of violent crime. In addition, women with a history of incarceration were much more likely to have perpetrated verbal or physical assault during a disagreement in the past 3 months and to have pushed, grabbed, shoved, or hit a main sexual partner in the past 30 days. Rates of sexual assault by several men at once were low and did not differ between groups.

Table 2 Health indicators by incarceration history $(n=720)$

\begin{tabular}{|c|c|c|c|}
\hline & $\begin{array}{l}\text { Ever incarcerated } \\
(n=25 I)\end{array}$ & $\begin{array}{l}\text { Never incarcerated } \\
(n=469)\end{array}$ & $\begin{array}{l}\text { Effect size } \\
\text { ( } 99 \% \text { confidence interval) }\end{array}$ \\
\hline \multicolumn{4}{|l|}{ Mental health } \\
\hline Depressive symptoms & $31.6 * * *(11.7)$ & $25.2(13.1)$ & $d=0.5 I(0.3 I-0.7 I)$ \\
\hline Anxiety symptoms & $20 . I^{* * *}(5.6)$ & $17.2(6.1)$ & $\mathrm{d}=0.50(0.30-0.7 \mathrm{I})$ \\
\hline Posttraumatic stress disorder symptoms & 36. I*** (9.9) & $30.5(11.1)$ & $d=0.53(0.32-0.73)$ \\
\hline \multicolumn{4}{|l|}{ Substance use } \\
\hline Frequent drinker (2+ times/week) & $35.1 \%$ & $43.3 \%$ & $\mathrm{OR}=0.7 \mathrm{I}(0.47-1.07)$ \\
\hline Extreme heavy drinker $(7+$ drinks/day) & $45.8 \% * *$ & $33.1 \%$ & $O R=1.71(1.13-2.59)$ \\
\hline \multicolumn{4}{|l|}{ Used the following in past 30 days? } \\
\hline Cannabis & $80.9 \%$ & $85.1 \%$ & $\mathrm{OR}=0.74(0.44-\mathrm{I} .26)$ \\
\hline Tik (methamphetamine) & $76.9 \% * * *$ & $56.7 \%$ & $\mathrm{OR}=2.54(1.61-4.00)$ \\
\hline Heroin & $7.6 \%$ & $5.3 \%$ & $\mathrm{OR}=1.45(0.65-3.27)$ \\
\hline Mandrax (methaqualone) & $37.1 \% * * *$ & $17.3 \%$ & $\mathrm{OR}=2.82(1.78-4.47)$ \\
\hline \multicolumn{4}{|l|}{ STIs and overall health } \\
\hline Have you ever been tested for HIV? & $80.9 \%$ & $85.7 \%$ & $\mathrm{OR}=0.70(0.4 \mathrm{I}-\mathrm{I} .20)$ \\
\hline $\begin{array}{l}\text { If tested, have you ever had an HIV } \\
\text { test come back positive? }\end{array}$ & $11.8 \%$ & $14.9 \%$ & $\mathrm{OR}=0.76(0.39-1.49)$ \\
\hline Currently has $2+\mathrm{STI}$ symptoms & $38.7 \% *$ & $28.6 \%$ & $\mathrm{OR}=1.57(\mathrm{I} .03-2.4 \mathrm{I})$ \\
\hline $\begin{array}{l}\text { In general, how is your health currently } \\
(I=\text { excellent, } 5=\text { poor })\end{array}$ & $2.4 * *(1.09)$ & $2.1(1.03)$ & $d=0.30(0.10-0.5 I)$ \\
\hline
\end{tabular}

Notes: ${ }^{*} P<0.01$; ${ }^{*} * P<0.001 ; * * * P<0.0001$; values in the table represent means and standard deviations, unless otherwise noted; ${ }^{2} n=605$.

Abbreviations: $d$, Cohen's d; OR, odds ratio. 
Table 3 Reasons for Using Drugs $(n=720)^{\mathrm{a}}$

\begin{tabular}{|c|c|c|c|}
\hline Do you use drugs ... & $\begin{array}{l}\text { Ever incarcerated \% } \\
(n=25 I)\end{array}$ & $\begin{array}{l}\text { Never incarcerated \% } \\
(n=469)\end{array}$ & $\begin{array}{l}\text { Odds ratio } \\
\text { ( } 99 \% \text { confidence interval) }\end{array}$ \\
\hline When you have an argument with a friend or family member? & $61.4 *$ & 50.1 & $1.58(1.05-2.38)$ \\
\hline When you feel sad or depressed? & $75.3^{*}$ & 64.4 & $1.69(1.07-2.65)$ \\
\hline When you want to have a good time? & 83.7 & 84.2 & $0.96(0.55-1.66)$ \\
\hline $\begin{array}{l}\text { When you are with other people who are drinking } \\
\text { or using other drugs? }\end{array}$ & 74. I*** & 52.7 & $2.57(1.65-4.00)$ \\
\hline When it is a special occasion or you feel like celebrating? & 83.7 & 80.0 & $1.28(0.76-2.18)$ \\
\hline $\begin{array}{l}\text { When you suddenly have a strong urge to drink or use } \\
\text { other drugs? }\end{array}$ & $76.9 * * *$ & 54.3 & $2.80(\mid .78-4.4 I)$ \\
\hline When you feel stressed and want to relax? & $84.1^{*}$ & 74.4 & $1.81(1.08-3.05)$ \\
\hline When you feel you are letting yourself down? & $68.9 * * *$ & 53.1 & $1.96(1.28-3.00)$ \\
\hline When you feel angry? & $74.9 * * *$ & 59.5 & $2.03(1.30-3.18)$ \\
\hline When you feel bored? & 63.4 & 53.5 & $1.50(0.99-2.27)$ \\
\hline When you are in (physical) pain? & $51.8 * * *$ & 30.3 & $2.47(1.63-3.75)$ \\
\hline When you have trouble sleeping? & $57.8^{*}$ & 46.7 & $1.56(1.04-2.34)$ \\
\hline
\end{tabular}

Notes: $* P<0.01$; ${ }^{* * P}<0.001$; $* * * P<0.0001$; a all 720 participants reported lifetime drug use.

\section{Effects of length of incarceration}

Finally, to explore whether women incarcerated for longer or shorter periods of time might have more need for services, associations between lifetime days incarcerated and variables significantly associated with "ever incarcerated" status in Tables 2-4 were examined in the ever incarcerated sample only $(\mathrm{n}=251)$ using Spearman correlations. No significant associations were found, suggesting that women incarcerated for shorter and longer periods of time had similar health needs.

\section{Discussion}

This study evaluated whether passing through the criminal justice system was associated with higher health risk across several domains in a sample of young, substance-using women in South Africa, a country with little previous research on the association between criminal justice involvement and health. As has been found in previous research, which has primarily taken place in North America, Europe, and Australia/New Zealand ${ }^{1,2,17,25,59}$, findings suggest that women who pass through criminal justice custody in South Africa are at elevated risk for a variety of health problems.

Specifically, as in other countries, findings indicated dramatically poorer current mental health in every tested domain (depressive symptoms, anxiety, post-traumatic stress symptoms) for ever incarcerated compared with never incarcerated women in South Africa. In fact, the average depression score among ever incarcerated women was twice the clinical cutoff; $88 \%$ of women with an incarceration history reported clinically significant ${ }^{54,60}$ levels of depression. These findings suggest that mental health screening and treatment at the time of intersection with the criminal justice system

Table 4 Physical and sexual victimization $(n=720)$

\begin{tabular}{|c|c|c|c|}
\hline & $\begin{array}{l}\text { Ever incarcerated } \\
(n=25 I)\end{array}$ & $\begin{array}{l}\text { Never incarcerated } \\
(n=469)\end{array}$ & $\begin{array}{l}\text { Effect size } \\
\text { ( } 99 \% \text { confidence interval) }\end{array}$ \\
\hline $\begin{array}{l}\text { Has anyone ever physically hurt you, striking or beating } \\
\text { you to the point you had bruises? }\end{array}$ & $60.2 \% * * *$ & $28.6 \%$ & $\mathrm{OR}=3.77(2.47-5.77)$ \\
\hline Abuse by current partner scale score ${ }^{a}$ & $9.2 * * *(9.9)$ & $5.4(8.8)$ & $\mathrm{d}=0.42(0.2 \mathrm{I}-0.63)$ \\
\hline Victim of violent crime, ever & $85.7 \% * * *$ & $66.3 \%$ & $\mathrm{OR}=3.03(1.79-5.14)$ \\
\hline Victim of violent crime, last 6 months? & $63.8 \% * * *$ & $45.0 \%$ & $\mathrm{OR}=2.15(1.42-3.25)$ \\
\hline $\begin{array}{l}\text { Has anyone ever forced you to participate in sexual acts } \\
\text { against your will? }{ }^{a}\end{array}$ & $30.7 \% * * *$ & $17.1 \%$ & $\mathrm{OR}=2.15(1.34-3.45)$ \\
\hline $\begin{array}{l}\text { Ever had sex with several men at the same time when you } \\
\text { didn't consent or you were forced? }\end{array}$ & $5.6 \%$ & $5.1 \%$ & $\mathrm{OR}=1.09(0.45-2.66)$ \\
\hline $\begin{array}{l}\text { Verbally or physically aggressive during a disagreement } \\
\text { in the past } 3 \text { months }\end{array}$ & $82.1 \% * * *$ & $58.0 \%$ & $\mathrm{OR}=3.32(2.04-5.40)$ \\
\hline $\begin{array}{l}\text { In the last } 30 \text { days, did you push, grab, shove, or hit your } \\
\text { main sexual partner? }\end{array}$ & $26.6 \% * * *$ & $14.3 \%$ & $\mathrm{OR}=2.18(1.30-3.64)$ \\
\hline
\end{tabular}

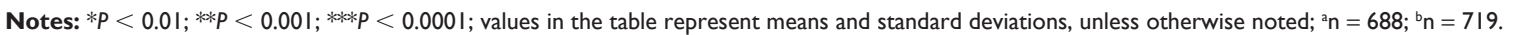

Abbreviations: $d$, Cohen's d; OR, odds ratio. 
could be helpful. In particular, women passing through criminal justice custody may benefit from information about how to manage or reduce depressive symptoms (such as exercise,${ }^{61,62}$ behavioral activation, ${ }^{63,64}$ and talking to supportive others ${ }^{65,66}$ ) and about how to manage or reduce symptoms of anxiety (such as exposure to feared thoughts, feelings, and situations, ${ }^{67,68}$ strategies for correcting cognitive errors, ${ }^{67,68}$ or relaxation/meditation practice ${ }^{69}$ ), especially symptoms associated with post-traumatic stress.

In addition, similar to findings in other countries, ${ }^{2}$ we found much higher rates of current and past victimization across almost all domains (abuse/control by current partner, physical injury, sexual assault, and victim of a variety of violent crimes both during their lifetime and more recently) for women who had ever been incarcerated relative to women with no incarceration history. The association between victimization and criminal justice involvement suggests that legal and treatment services, as well as information about self-care and resources for women experiencing violence or control by current partners, at the time of criminal justice involvement may be helpful. Physical and psychological treatment for trauma sequelae is also needed. In addition, trauma-sensitive prison policies and procedures may also be helpful because the male prison model, which can include internal physical searches, gross power imbalances between prison staff and inmates, privacy violations, and verbal or physical belittlement, can evoke memories of past victimization. ${ }^{2}$ In addition, ever incarcerated women reported much higher rates of current aggression toward intimate partners and others than did other women in our sample, suggesting that there may be a need to teach women passing through criminal justice custody alternate ways to address disagreements and to ensure their own safety in a cultural context that is very violent. This treatment should be sensitive to the fact that women may see violence as the only way to cope or to protect themselves and their children from the violence around them, especially when their families or the police have failed to protect them. ${ }^{28}$

As with findings in other countries, women passing through the criminal justice system in South Africa reported more problematic substance use than did other women in the sample. Findings are notable given that all women in the sample reported problematic substance use. Findings suggest that treatment and screening for drug use and for extreme heavy drinking for women passing through the criminal justice system may be warranted. As hypothesized, women with an incarceration history were more likely than other women to report pain- and distress-related reasons for using drugs. They were also more likely to endorse reasons for using drugs that were related to a perceived inability to resist urges or to refrain from drug use when others are using. The fact that women with an incarceration history reported more pain- and distress-related reasons for using drugs, as well as poorer mental health and more victimization relative to other women, suggests that substance use treatment in the criminal justice system should carefully consider co-occurring mental health issues and trauma. Treatment might also focus more than usual on managing pain and distress without substance use, on managing urges and cravings in response to others' use, and on managing the cultural context of poverty stricken areas, in which women are surrounded with substance use, stress, and violence. In the US, women are often told to change their environments and negative social supports, but in poor South African communities, women do not have many choices and often need coping mechanisms for a healthier way of daily survival.

As with research in other countries, findings suggested that women who had passed through the criminal justice system had poorer overall health and were more likely to have multiple STI symptoms. However, unlike the findings of most previous research in other countries, women in our sample who had ever been incarcerated were not more likely to report awareness of having HIV. This may be because incarceration history is not associated with HIV risk for women in the Western Cape. It may also be because the sample was selected for high HIV risk. For example, about $14 \%$ of women who had been tested for HIV in this sample reported awareness of receiving a positive test. It is also possible that women were not aware of their current HIV status; the lack of current biological confirmation of HIV status is a limitation of this manuscript. In any case, health and STI screening for women passing through criminal justice custody seems warranted. The provision of basic information about safe sex and any low-cost general healthcare resources may also be helpful.

The fact that the index incarceration may have only lasted for a day, and may have happened many years before, means that no-difference findings should be interpreted with caution. However, the fact that a potentially day-long incarceration at any point in a woman's life is associated with current health and behavior suggests that incarceration is a strong marker for current and future health risk. Furthermore, recruiting only young, substance using, and mostly poor women assumed to be at high risk across several domains probably restricted the range of substance use and other health risk variables in this sample (ie, no low-risk participants). As a result, the 
association between criminal justice involvement and health risk is likely to be stronger in samples with a wider range of health risk, such as community or representative samples of South African women.

Strengths of the study include a large sample, little missing data, and the ability to address the association of criminal justice and health in a population that has been the subject of little previous research in this area. One limitation is the cross-sectional, retrospective study design, although this matters less when the goal of the study is to establish lifetime association rather than temporal association or causality. With so many comparisons, it is possible that some cross-cutting characteristic may underlie many of the findings. However, the purpose of the study was not to explain health disparities but only to determine whether they existed and could be defined by contact with the criminal justice system as one potential point of intervention. A second limitation is that because this is a secondary analysis, some areas salient to the intersection of criminal justice and health were not assessed. The association of criminal justice involvement with rates of tuberculosis, hepatitis B and C, biologically confirmed HIV, drug or alcohol overdose, specific mental health disorders, and lifetime suicide attempts and self-harm should be evaluated in future studies.

Because passing through the criminal justice system is associated with higher lifetime and future health risk across many domains, intervening at the time of incarceration may reduce the health burden for a vulnerable subset of South African women. Policies that provide screening, prevention, and treatment relevant to mental health, substance use, traumatic victimization, violent aggression, overall health, and HIV/STI risk for women passing through the South African criminal justice system would be ideal. In fact, incarcerated South African women have requested these services. ${ }^{39}$ However, such screening and treatment services can be costly and many women spend only one to a few days in criminal justice custody. Our findings suggested that women incarcerated briefly need services as much as do women incarcerated for longer periods of time. A spectrum of less intensive interventions, such as classes, meetings with peer educators, videos, simple brochures, one-page fact sheets, or referrals to additional resources may be helpful in beginning to address their needs. Regardless of the exact method of intervention provided, our findings suggest that mental health, substance use, and infectious disease screening and intervention services for women passing through criminal justice custody are warranted, especially around issues of traumatic victimization.

\section{Acknowledgment}

This work was supported by grants K23DA021159 from the National Institute of Drug Abuse (NIDA, PI: Johnson) and by 5R01HD058320 from the Eunice Kennedy Shriver National Institute of Child Health and Human Development (NICHD, PI: Wechsberg).

\section{Disclosure}

The authors have no conflicts of interest to declare.

\section{References}

1. Fazel S, Baillargeon J. The health of prisoners. Lancet. 2011;377: 956-965.

2. Moloney KP, van den Bergh BJ, Moller LF. Women in prison: The central issues of gender characteristics and trauma history. Public Health. 2009; 123:426-430.

3. Walmsley R. World Prison Population List. 8th ed. London: King's College London International Centre for Prison Studies; 2009.

4. Dolan K, Kite B, Black E, Aceijas C, Stimson GV; Reference Group on HIV/AIDS Prevention and Care among Injecting Drug Users in Developing and Transitional Countries. HIV in prison in low-income and middle-income countries. Lancet Infect Dis. 2007;7:32-41

5. Correctional Services of the Republic of South Africa. Gender incarceration levels as on the last day of 2011/02. Available from: http://www.dcs.gov.za/AboutUs/StatisticalInformation.aspx. Accessed September 14, 2011.

6. Correctional Services of the Republic of South Africa. Inmates per Crime Category as on the last day of 2011/02. Available from: http:// www.dcs.gov.za/AboutUs/StatisticalInformation.aspx. Accessed September 14, 2011.

7. Fagan J; for Office of the Inspecting Judge of Prisons for the Republic of South Africa. Annual Report for April 1, 2005 to March 31, 2006. Available from: http://judicialinsp.pwv.gov.za/Annualreports/ ANNUAL\%20REPORT\%202006.pdf. Accessed September 15, 2011.

8. Pew Research Center for the People and the Press. One in 100: Behind Bars in America, 2008. Available from: http://www.pewcenteronthestates.org/report_detail.aspx?id=35904. Accessed October 24, 2011.

9. Statistics South Africa. Mid-year population estimates: 2010. Available from: http://www.statssa.gov.za/publications/P0302/P03022010.pdf. Accessed July 23, 2011.

10. Correctional Services of the Republic of South Africa. Inmate gender and racial composition as on the last day of 2011/02. Available from: http://www.dcs.gov.za/WebStatistics/inmate-gen.aspx. Accessed October 24, 2011.

11. Gibbons J. Women prisoners and South Africa. Prison Journal. 1998;78:330-343.

12. Luyt W. Imprisoned mothers in South African prisons with children outside of the institution. European Journal of Crime, Criminal Law and Criminal Justice. 2008;16:299-323.

13. Sifunda S, Reddy PS, Braithwaite RB, et al. The relationship between alcohol and drug use and sexual behaviour amongst prison inmates in developing countries: The case of South Africa. International Journal of Prisoner Health. 2007;3:3-15.

14. Sanders D, Chopra M. Key challenges to achieving health for all in an equitable society: the case of South Africa. Am J Public Health. 2006;96:73-78.

15. Coovadia H, Jewkes R, Barron P, Sanders D, McIntyre D. The health and health system of South Africa: historical roots of current public health challenges. Lancet. 2009;374: 817-834. 
16. Luseno WK, Wecshberg WM, Kline TL, Ellerson RM. Health services utilization among south african women living with HIV and reporting sexual and substance-use risk behaviors. AIDS Patient Care STDs. 2010;24:257-264

17. Fazel S, Danesh J. Serious mental disorder in 23,000 prisoners: a systematic review of 62 surveys. Lancet. 2002;359:545-550.

18. Jordan BK, Schlenger WE, Fairbank JA, Caddell JM. Prevalence of psychiatric disorder among incarcerated women. II. Convicted felons entering prison. Arch Gen Psychiatry. 1996;53:513-519.

19. Teplin LA, Abram KM, McClelland GM. Prevalence of psychiatric disorders among incarcerated women. I. Pretrial jail detainees. Arch Gen Psychiatry. 1996;53:505-512.

20. Kessler RC, Sonnega A, Bromet E, Hughe M, Nelson CB. Posttraumatic stress disorder in the National Comorbidity Survey. Arch Gen Psychiatry. 1995;52:1048-1060.

21. Lewis C. Treating incarcerated women: gender matters. Psychiatr Clin North Am. 2006;29:773-789.

22. Lenzenweger MF, Lane MC, Loranger AW, Kessler RC. DSM-IV personality disorders in the national comorbidity survey replication. Biol Psychiatry. 2007;62:553-564.

23. Kessler RC, Nelson CB, McGonagle KA, Liu J, Swartz M, Blazer DG. Comorbidity of DSM-III-R major depressive disorder in the general population: results from the US National Comorbidity Survey. Br J of Psychiatry Suppl. 1996;168:17-30.

24. Kessler RC, Birnbaum H, Demler O, et al. The prevalence and correlates of nonaffective psychosis in the National Comorbidity Survey Replication (NCS-R). Biol Psychiatry. 2005;58:668-676.

25. Fazel S, Bains $\mathrm{P}$, Doll H. Substance abuse and dependence in prisoners: a systematic review. Addiction. 2006;101:181-191.

26. Rocha-Silva L, Stahmer I. Nature, Extent, and Development of Alcohol/Drug-Related Crime. Pretoria: Human Sciences Research Council; 1996.

27. Parry CD, Püddermann A, Louw A, Leggett T. The 3-Metros Study of Drugs and Crime in South Africa: findings and policy implications. Am J Drug Alcohol Abuse. 2004;30:167-185.

28. Pretorius HG, Botha S. The cycle of violence and abuse in women who kill an intimate male partner: a biographical profile. South African Journal of Psychology. 2009;39:242-252.

29. McQuillan GM, Kruszon-Moran D. HIV infection in the United States household populations aged 18-49 years: Results from 1999-2006. NCHS Data Brief. 2008;4:1-8.

30. Hammett TM. Sexually transmitted diseases and incarceration. Curr Opin Infect Dis. 2009;22:77-81.

31. Datta SD, Sternberg M, Johnson RE, et al. Gonorrhea and Chlamydia in the United States among Persons 14 to 39 Years of Age, 1999-2002. Ann Intern Med. 2007;147:89-96.

32. Gottlieb SL, Pope V, Sternberg MR, Beltrami MR, Berman JF, Markowitz L. Prevalence of Syphilis Seroreactivity in the United States: Data from the 2001-2002 National Health and Nutrition Examination Survey (NHANES). National STD Prevention Conference: Jacksonville, FL; May 10, 2006.

33. Clarke JG, Hebert MR, Rosengard C, Rose JS, DaSilva KM, Stein MD. Reproductive health care and family planning needs among incarcerated women. Am J Public Health. 2006;96:834-839.

34. Hale GJ, Oswalt KL, Cropsey KL, Villalobos GC, Ivey SE, Matthews CA. The contraceptive needs of incarcerated women. J Womens Health (Larchmt). 2009;18:1221-1226.

35. Goyer KC. HIV/AIDS in prison: problems, policies, and potential. Institute for the Security Studies Monographs. 2003;Monograph 79:103.

36. Wilper A, Woolhandler S, Boyd JW, et al. The health and health care of US prisoners: results of a nationwide survey. Am J Public Health. 2009;99:666-672.

37. Haffajee S, Vetten L, Greyling M. Minority report: The imprisonment of women and girls in Gauteng. Centre for the Study of Violence and Reconciliation, CSVR Gender Programme, Research Brief No. 4, Feb 2006.
38. Statistics South Africa. Perceived health and other health indicators in South Africa, 2004. Available from: http://www.statssa.gov.za/ publications/HealthOHS/HealthOHS1999.pdf. Accessed September 23, 2011.

39. Haffajee S, Vetten L, Greyling M. Exploring violence in the lives of women and girls incarcerated at three prisons in Gauteng Province, South Africa. Agenda. 2006;19:40-47.

40. Haffejee S, Vetten L, Greyling M. Violence and abuse in the lives of women and girls incarcerated at three Gauteng women's prisons. Centre for the Study of Violence and Reconciliation, CSVR Gender Programme, Research Brief No. 3, Feb 2006.

41. Wechsberg WM, Luseno WK. The need for culturally appropriate, gender-specific global HIV prevention efforts with vulnerable women. J Prev Interv Community. 2010;38:85-88.

42. Wechsberg WM, Luseno WK, Karg RS, et al. Alcohol, cannabis, and methamphetamine use and other risk behaviours among Black and Coloured South African women: a small randomized trial in the Western Cape. Int J Drug Policy. 2008;19:130-139.

43. Jones HE, Browne FA, Myers BJ, et al. Pregnant and nonpregnant women in Cape Town, South Africa: drug use, sexual behavior, and the need for comprehensive services. Int J Pediatr. 2011:Article ID 353410. Epub April 6, 2011.

44. Seedat M, Van Niekerk A, Jewkes R, Suffla S, Ratele K. Violence and injuries in South Africa: prioritising an agenda for prevention. Lancet. 2009;374:1011-1022.

45. Doyle SR, Donovan DM, Simpson TL. Validation of a nine-dimensional measure of drinking motives for use in clinical applications: the desired effects of drinking scale. Addict Behav. 2011;36: 1052-1060.

46. Langan NP, Pelissier BM. Gender differences among prisoners in drug treatment. J Subst Abuse. 2001;13:291-301.

47. Ullman SE, Filipas HH, Townsend SM, Starzynski LL. Trauma exposure, posttraumatic stress disorder and problem drinking in sexual assault survivors. J Stud Alcohol. 2005;66:610-619.

48. Stewart SH, Karp J, Pihl RO, Peterson RA. Anxiety sensitivity and self-reported reasons for drug use. J Subst Abuse. 1997;9: 223-240.

49. Young AM, Boyd C, Hubbell A. Prostitution, drug use, and coping with psychological distress. Journal of Drug Issues. 2000;30: 789-800.

50. Wechsberg WM. Revised Risk Behavior Assessment, Part I and Part II. Research Triangle Park (NC): Research Triangle Institute; 1998.

51. Wechsberg WM, Luseno WK, Lam WK, Parry CD, Morojele NK. Substance use, sexual risk, and violence: HIV prevention intervention with sex workers in Pretoria. AIDS Behav. 2006;10:131-137.

52. Wechsberg WM, Luseno WK, Kline T L, Browne FA, Zule WA. Preliminary findings of an adapated evidence-based woman-focused HIV interventionon condom use and negotiation among at-risk women in Pretoria, South Africa. J Prev Interv Community. 2010;38:132-146.

53. Wechsberg WM, Wu LT, Zule WA, et al. Substance abuse, treatment needs and access among female sex workers and non-sex workers in Pretoria, South Africa. Subst Abuse Treat Prev Policy. 2009;4:11.

54. Radloff LS. A CES-D scale: a self-report depression scale for research in the general population. Applied Psychological Measurement. 1977;1:385-401.

55. Simpson D. Drug Abuse Treatment for AIDS Risk Reduction (DATAR): Forms Manual. Fort Worth (TX): Texas Christian University; 1990.

56. Dennis M, Titus JC, White M, et al. Global Appraisal of Individual Needs (GAIN). 5th ed. Bloomington (IL): Chestnut Health Systems; 2002.

57. World Health Organization. WHO Multi-Country Study on Women's Health and Domestic Violence: Core Questionnaire and WHO Instrument. 9th ed. Geneva, Switzerland: World Health Organization; 2000 .

58. Wechsberg WM, Lam WK, Zule WA, Hall G, Middlesteadt R, Edward J. Violence, homelessness and HIV risk among crack-using AfricanAmerican women. Subst Use Misuse. 2003;38:669-700. 
59. Goff A, Rose E, Rose S, Purves D. Does PTSD occur in sentenced prison populations? A systematic literature review. Crim Behav Ment Health. 2007; 17:152-162.

60. Hamad R, Fernald LC, Karlan DS, Zinman J. Social and economic correlates of depressive symptoms and perceived stress in South African adults. J Epidemiol Community Health. 2008;62:538-544.

61. Conn VS. Depressive symptom outcomes of physical activity interventions: meta-analysis findings. Ann Behav Med. 2010;39: $128-138$

62. Rethorst CD, Wipfli BM, Landers DM. The antidepressive effects of exercise: a meta-analysis of randomized trials. Sports Med. 2009;39:491-611.

63. Mazzucchelli T, Kane R, Rees C. Behavioral activation treatments for depression in adults: a meta-analysis and review. Clinical Psychology: Science and Practice. 2009;16:383-411.

64. Cuijpers P, van Straten A, Warmerdam L. Behavioral activation treatments of depression: a meta-analysis. Clin Psychol Rev. 2007;27:318-326.
65. Mead N, Lester H, Chew-Graham C, Gask L, Bower P. Effects of befriending on depressive symptoms and distress: systematic review and meta-analysis. Br J Psychiatry. 2010;196:96-101.

66. Weissman M, Markowitz J, Klerman G. Comprehensive Guide to Interpersonal Psychotherapy. New York: Basic Books; 2000.

67. Olatunji BO, Cisler JM, Deacon BJ. Efficacy of cognitive behavioral therapy for anxiety disorders: a review of meta-analytic findings. Psychiatr Clin North Am. 2010;33:557-577.

68. Norton PJ, Price EC. A meta-analytic review of adult cognitivebehavioral treatment outcome across the anxiety disorders. J Nerv Ment Dis. 2007;195:521-531.

69. Manzoni GM, Pagnini F, Castelnuovo G, Molinari E. Relaxation training for anxiety: a ten-years systematic review with meta-analysis. BMC Psychiatry. 2008;8:41

\section{Publish your work in this journal}

Substance Abuse and Rehabilitation is an international, peer-reviewed, open access journal publishing original research, case reports, editorials, reviews and commentaries on all areas of addiction and substance abuse and options for treatment and rehabilitation. The manuscript management system is completely online and includes a very quick and fair peer-review system. Visit http://www.dovepress.com/testimonials.php to read real quotes from published authors. 